\title{
Recuperação e Monitoramento de Dados Utilizando a Rede de Transporte Público
}

\author{
Rafael Cordeiro, Mauro Fonseca, Anelise Munaretto, Thiago A. Herek \\ ${ }^{1}$ Programa de Pós Graduação em Engenharia Elétrica e Informática Industrial (CPGEI) \\ Universidade Tecnológica Federal do Paraná (UTFPR). \\ Av. Sete de Setembro, 3165. CEP 80230-901. Curitiba, Brazil. \\ \{rafaelcordeiro, maurofonseca, anelise, therek\}@utfpr.edu.br
}

\begin{abstract}
Resumo. Este artigo apresenta uma proposta de encaminhamento de mensagens testada com o modelo de mobilidade da Rede Integrada de Transporte Coletivo de Curitiba. A proposta inclui uma adaptação no protocolo Spray and Wait baseada na categorização dos veículos do transporte coletivo da cidade, priorizando a transmissão das mensagens para os ônibus que apresentam uma maior proximidade lógica com o destino. Em seguida, a proposta foi avaliada utilizando traços reais e um modelo de tráfego voltado para aplicações de monitoramento. Os resultados obtidos comprovam os ganhos da estratégia proposta, apresentando melhores taxas de entrega, menor atraso e menor sobrecarga quando comparados aos protocolos clássicos.
\end{abstract}

\section{Introdução}

Em um ambiente urbano, o monitoramento da cidade pode ser realizado através de uma rede composta por veículos utilizados como plataformas de sensoriamento para a coleta e disseminação de dados através de uma rede ad-hoc veicular (VANET) [Herek et al. 2018]. Redes VANETs são consideradas como uma extensão das redes ad-hoc móveis (MANETs). Em uma VANET, cada veículo funciona como um roteador de uma rede autoorganizada, tendo o papel de viabilizar a comunicação entre os membros dessa rede por meio de ondas de rádio. O objetivo principal de uma VANET é prover conectividade entre os veículos, permitindo que os mesmos troquem informações entre si, a fim de fornecer suporte a diversas aplicações, costumeiramente classificadas em três categorias, conforme suas funcionalidades: segurança, eficiência e sistemas de transporte inteligentes [Kai et al. 2016].

Nas VANETs, os veículos podem se comunicar por meio de quatro arquiteturas diferentes: veículo-a-veículo (V2V), veículo-a-infraestrutura (V2I), híbrida e veículo-apassageiro (V2P) [Kakkasageri and Manvi 2014]. Essa comunicação é intermitente e sofre com frequentes atrasos e desconexões devido à movimentação dos veículos. Considerando as limitações de alcance dos sistemas dedicados de curta distância, os veículos membros dessa rede poderiam encontrar-se dispersos em um ambiente com baixa densidade e conectividade. Neste caso, DTNs (Delay tolerant networks) são utilizadas como uma das principais alternativas para prover conectividade [Uchida et al. 2015]. Ao utilizar o mecanismo de store-carry-and-forward, as DTNs possibilitam que os veículos armazenem o pacote a ser transmitido até ser possível que o mesmo seja encaminhado para um veículo intermediário, assim sucessivamente até alcançar o seu destino. Dessa maneira, um veículo vale-se de sua mobilidade para repassar os dados armazenados em 
possíveis encontros com outros veículos, permitindo o uso de aplicações tolerantes a atraso [Ahmed et al. 2015]. O modelo a ser utilizado nesse trabalho é o modelo híbrido, combinando as estruturas V2V e V2I, uma vez que os veículos trocam mensagens entre si e entregam as mesmas para uma antena fixa, que nos testes está localizada na região central de Curitiba.

Quanto à camada física, o IEEE (Institute of Electrical and Electronics Engineers) desenvolve a arquitetura para a pilha de protocolo adaptada para ambientes VANETs, conhecida como WAVE (Wireless access in vehicular environments), composta, entre outros pelo padrão IEEE 802.11p, desenvolvido com base no 802.11a para sustentar a comunicação sem fio ad hoc em ambientes V2V e V2I, definindo a operação da camada física e do controle de acesso ao meio em comunicações de curta distância [Awang et al. 2017].

A implantação de uma rede veicular em uma cidade depende da comunicação entre os veículos que fazem parte da mesma, os quais devem ser capazes de se comunicar, utilizando a mesma tecnologia de transmissão sem fio e os mesmos protocolos de rede. O fato dos ônibus do transporte público estarem sob controle de uma mesma organização sugere uma padronização, favorecendo tal implantação. Outra característica favorável dos ônibus é que os mesmos estão presentes em todos os espaços das cidades, apresentando uma grande cobertura, dos bairros centrais aos periféricos, facilitando a sua utilização em uma VDTN (Vehicular delay tolerant network) [Zhang et al. 2017] e permitindo o uso de diversas aplicações úteis à sociedade, sem os custos de outras redes, tais como as celulares (3G/4G). Dentre as aplicações possíveis, o modelo de tráfego de dados irá utilizar como exemplo uma aplicação de monitoramento, na qual todos os veículos informam, em intervalos regulares de tempo, informações referente à sua posição geográfica, bem como dados relativos ao monitoramento (hipoteticamente em uma aplicação de monitoramento ambiental, temperatura, nível de poluição e umidade) à uma central localizada na Praça Rui Barbosa, região central da cidade, cuja posição em relação ao traçado das linhas é demonstrada na figura 1.

O principal objetivo deste trabalho é apresentar um novo protocolo para uma rede veicular tolerante a atrasos e desconexões customizado para aproveitar-se das características inerentes ao ambiente proposto. Nossa proposta será baseada no Spray and Wait [Spyropoulos et al. 2005], escolhido devido a sua alta escalabilidade, ideal na utilização em cenários com uma grande quantidade de veículos, além de possibilitar a limitação da quantidade de cópias de mensagens a serem transmitidas, diminuindo a sobrecarga na rede. Para validação da proposta foi construído um cenário de simulação abrangente utilizando os dados reais da cidade de Curitiba [Dados Abertos URBS 2019] e o simulador One [Keränen et al. 2009]. Serão executadas simulações comparando a nossa proposta com os protocolos Epidêmico, Prophet e Spray and Wait, já disponíveis no simulador.

O conteúdo subsequente deste trabalho está organizado da seguinte forma. A seção 2 consiste em uma revisão da literatura e citação de trabalhos relacionados ao tema. A seção 3 dispõe a construção do modelo de mobilidade, utilizando a proposta com os dados reais de Curitiba. A seção 4 descreve as alterações realizadas no protocolo Spray and Wait, enquanto que na seção 5 são apresentados e discutidos os resultados. Por fim, na Seção 6 são tecidas as conclusões e possíveis trabalhos futuros são discutidos. 


\section{Revisão da Literatura}

\subsection{Protocolos de Roteamento VTDN}

Iremos utilizar três protocolos de roteamento em nossas avaliações: Epidêmico, Prophet e Spray and Wait, além de nossa modificação proposta, baseada no protocolo Spray and Wait.

O protocolo Epidêmico [Vahdat and Becker 2000] tem como principal objetivo entregar a maior quantidade de mensagens com o menor atraso possível. Para atingir tal objetivo, ele utiliza uma técnica de inundação pura da rede, na qual todas as mensagens são repassadas a todos os nós ao alcance do raio de comunicação.

Já o protocolo Prophet [Lindgren 2012] é uma variação do protocolo Epidêmico, mas que limita a inundação de mensagens na rede através de mecanismos que estimam a previsibilidade de cada nó entregar a mensagem. Dessa maneira, o nós com maior previsibilidade de entrega são favorecidos nas decisões de roteamento.

O protocolo Spray and Wait [Spyropoulos et al. 2005] por sua vez utiliza uma inundação controlada com o objetivo de diminuir a sobrecarga na rede. É dividido em duas fases: Na fase de Spray ou pulverização, um número definido e limitado de réplicas é transmitido da origem para os nós vizinhos. Caso o destino não seja encontrado durante a fase de pulverização, o nó de origem entra na fase de Wait, na qual ele aguarda até que alguma das réplicas seja entregue ao destino. A propagação das cópias pode ocorrer de duas maneiras: normal e binária. No modo normal, cada réplica é encaminhada do nó origem para o vizinho, enquanto que no modo binário metade das cópias é transmitida a cada encontro com um nó vizinho, assim sucessivamente, até que cada nó fique com apenas uma cópia da mensagem.

\subsection{Trabalhos Relacionados}

Estudos anteriores demonstram a crescente preocupação com a questão do monitoramento em cidades. Os trabalhos seguintes possuem similaridades com o trabalho proposto no que diz respeito à questões de monitoramento em ambientes urbanos e à construção de redes DTN utilizando informações GPS de veículos. Em [Radu et al. 2012], os autores propõem o desenvolvimento de uma rede veicular ad-hoc com o objetivo de coletar dados de telefones celulares equipados com GPS e utilizados como detectores de ruído. Os autores propõem uma solução de roteamento para os dados disseminados através da VANET utilizando o protocolo MP-OLSR, uma modificação do protocolo OLSR que faz uso de múltiplos caminhos para realizar o encaminhamento dos pacotes, apresentando uma melhor taxa de entrega e menor atraso quando comparado ao protocolo original.

Já [Tudose et al. 2011] apresentam em seu trabalho um sistema móvel de monitoramento da qualidade do ar adequado para ambientes urbanos e testado na cidade Bucareste-Romênia, baseado em dispositivos portáteis capazes de detectar altas concentrações de poluentes na atmosfera. As informações coletadas são armazenadas juntamente às coordenadas do local, e transferidas periodicamente até um computador por meio de uma conexão GPRS. Os autores enfatizam o potencial de uma arquitetura multi-agente com diversos dispositivos coletores trabalhando em conjunto com a possibilidade de serem instalados em veículos do transporte público, a fim de fornecer uma visão precisa da poluição gerada pelo tráfego. 
No contexto de VANETs, estudos anteriores a este trabalho exploram a utilização do transporte urbano na implementação de uma rede veicular tolerante a atrasos e desconexões. Em seu trabalho, [Dias and Costa 2016] estudam a viabilidade de criação de redes DTN, utilizando as posições reportadas pelos ônibus da cidade do Rio de Janeiro através das informações GPS, concluindo que é possível transferir uma quantidade expressiva de dados em um período de $24 \mathrm{~h}$.

Por sua vez, [Herek et al. 2018] demonstra através de simulações que é possível utilizar aplicações úteis, como monitoramento de frota e envio de avisos e notícias em um ambiente composto pela rede de transporte urbano de Curitiba. Em seu trabalho subsequente, [Herek 2018] utiliza a mesma rede na implementação de um ambiente VTDN. O modelo de mobilidade foi projetado para representar toda a malha viária dos ônibus que circulam pela cidade, sendo construído por meio do uso de dados reais, oferecendo condições de avaliação da capacidade do ambiente e o aprimoramento de protocolos de roteamento para redes VTDNs. No mesmo trabalho, o autor apresenta e avalia os protocolos Spray and Wait Bus e Prophet-Bus como modificações dos protocolos originais Spray and Wait e Prophet. O objetivo das alterações propostas é aprimorar métricas (taxa de entrega, atraso e sobrecarga), valendo-se das características do ambiente para um melhor aproveitamento do contato entre os nós. Adicionalmente, o autor apresenta os resultados das simulações obtidas utilizando os protocolos modificados, comparando estes dados com os obtidos através dos protocolos originais.

\section{Modelo de Mobilidade}

O modelo de mobilidade é um fator altamente relevante no que diz respeito à avaliação dos resultados obtidos em uma simulação. Em [Fiore et al. 2014] são descritos alguns aspectos que devem ser levados em consideração ao definir um modelo de mobilidade. O modelo deve representar o tráfego de maneira integral, com atualizações frequentes da posição dos veículos e uma descrição fiel do layout das ruas e sua sinalização. Além disso, deve fornecer uma representação realista do comportamento dos condutores, tanto individual como coletivamente.)

A cidade de Curitiba abrange uma área de aproximadamente $435 \mathrm{Km} 2$, sendo a maior do sul do País, com uma população total de aproximadamente 1.893.000 habitantes [Instituto Brasileiro de Geografia e Estatistica 2017]. O sistema viário contém $4.325 \mathrm{Km}$ de vias pavimentadas, das quais $1.183 \mathrm{Km}$ são cobertas pela rede de transporte coletivo, que possui mais de 250 linhas e 1280 veículos em operação (os quais percorrem em média 303.707 Km por dia) [Companhia de Urbanização da Cidade de Curitiba 2017, Instituto de Pesquisa e Planejamento Urbano de Curitiba 2017].

As características do transporte coletivo em grandes cidades sugerem a sua utilização como uma solução promissora na construção de redes veiculares [Zhang et al. 2017]. Dentre essas características, podemos citar algumas que contribuem para a criação de uma VANET para coleta e disseminação de mensagens de monitoramento:

- Área de cobertura: por ser projetado para cobrir grande parte da cidade e utilizar uma grande quantidade de veículos, é ideal para monitorar a cidade como um todo, coletando informações tanto nas áreas centrais, como nas regiões mais afastadas da cidade. 
- Malha de conectividade: a existência de terminais de ônibus para integração entre as linhas favorece os encontros entre os veículos e consequentemente a troca de mensagens entre os mesmos.

- Aproveitamento de recursos existentes: a independência de infraestrutura adicional no aproveitamento dos ônibus para a coleta das informações favorece o esforço de implementação.

- Homogeneidade: o fato do controle da frota ser realizado por uma mesma entidade sugere uma homogeneidade entre os veículos facilitando a comunicação entre os mesmos devido à questões de padronização das tecnologias empregadas.

Neste trabalho, todo o cenário do transporte urbano da cidade de Curitiba é representado utilizando as posições geográficas de cada veículo. Os dados são obtidos por meio de módulos GPS instalados em todos os veículos e são fornecidos pela Companhia de Urbanização da Cidade de Curitiba (URBS) [Companhia de Urbanização da Cidade de Curitiba 2017] por meio da página de Dados Abertos da cidade de Curitiba [Dados Abertos URBS 2019]. Todos os dados gerados nos dias avaliados foram convertidos para o formato reconhecido no módulo External Movement do software simulador The One.

Essa forma de representação permite manter a fidelidade das características do ambiente veicular, pois não procura simular artificialmente as condições de tráfego e sinalizações de trânsito, mas efetivamente transporta para o simulador os movimentos observados no ambiente real, sendo neste caso uma das contribuições deste trabalho e uma evolução do modelo proposto por [Herek 2018]. Em tal trabalho, é utilizada a posição dos pontos de parada ou terminais de ônibus como referência de itinerário a ser percorrido por cada veículo, e por meio dos mesmos dados GPS calcula-se os valores médios de velocidade, tempo de parada nos pontos, bem como a quantidade veículos em operação em cada uma das linhas em operação, afim de simular o movimento de todo sistema do transporte público urbano, dentro de seu traçado real.

Nos dados obtidos por GPS utilizado para a extração da mobilidade deste presente trabalho, cada veículo informa sua posição a cada 11 segundos em média, fornecendo informações como identificação do veículo, latitude, longitude e a hora no formato (hh:mm:ss hora,minuto,segundo), entre outras. A partir destes dados, são convertidos todos os parâmetros de posicionamento para o formato Well-known text (WKT), reconhecido pelo simulador. Por fim, a tupla de dados utilizada para transportar essas informações para módulo External Movement, segue a seguinte formatação (TEMPO,IDVEICULO,LAT,LONG), onde cada registro identifica o instante de tempo em que determinado veículo estava em uma posição posição $(\mathrm{X}, \mathrm{Y})$.

Em posse dos dados necessários, o software simulador reconhece a posição inicial do veículo e o movimenta para a próxima posição GPS no tempo registrado na tupla. O deslocamento dos carros entre uma posição e outra, utiliza a diferença de tempo e a distância entre os dois pontos coletados para determinar a velocidade média de movimentação no trecho. Este processo se repete com a próxima posição GPS e assim por diante até o fim da simulação e por meio deste método, transportamos as características do transporte público de Curitiba para o simulador com uma precisão significativa. Na figura 1 temos o comparativo do traçado real de todas as linhas do transporte público urbano de Curitiba com a representação das posições GPS coletadas de todos os veículos. 

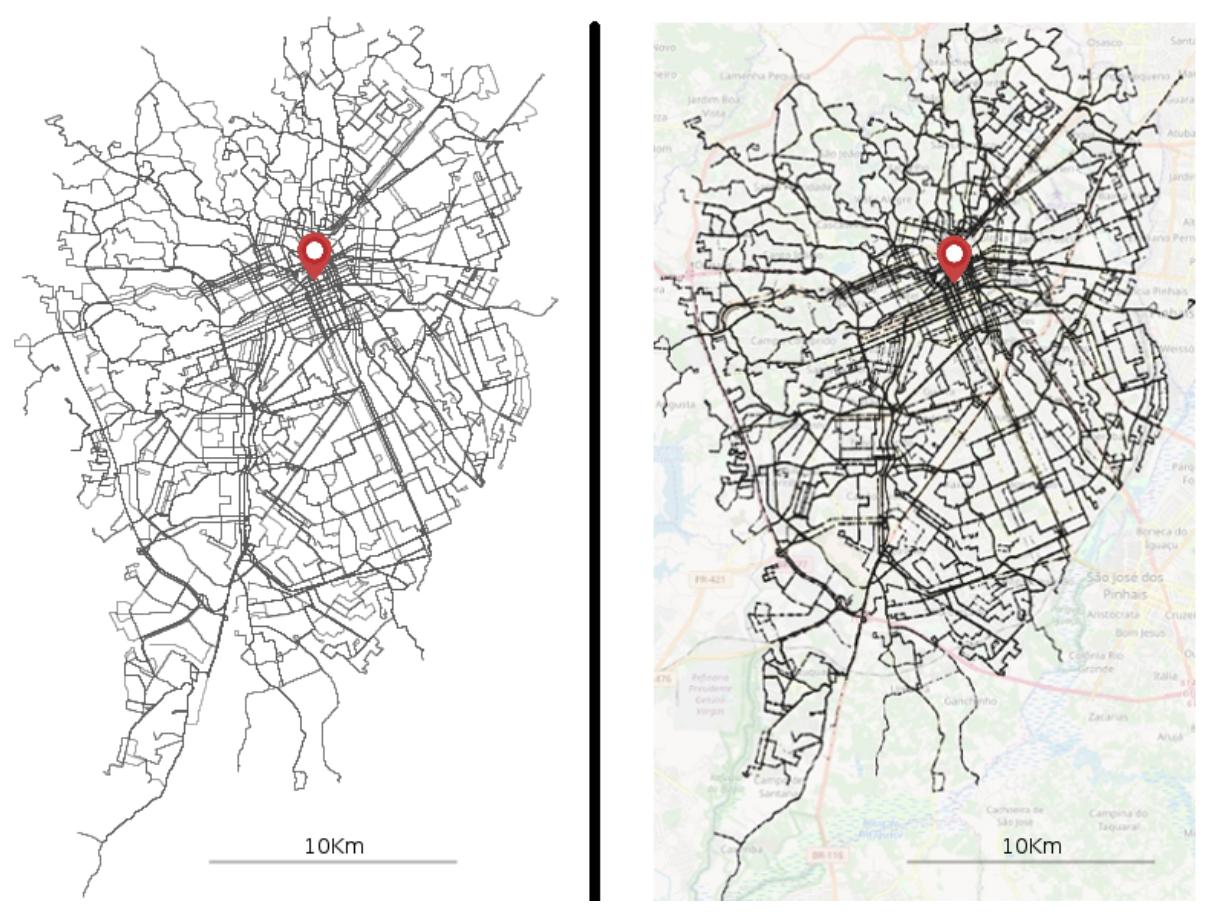

Figura 1. Do lado esquerdo, o traçado real das linhas de ônibus. Do lado direito, as posições GPS coletadas de todos os veículos, revelando as semelhanças entre o traçado real e a representação de todas as posições informadas por GPS. Em destaque, a localização da Praça Rui Barbosa, nos testes utilizada como destino das mensagens.

\subsection{Modelo de Tráfego de Dados}

Em uma simulação, o modelo de tráfego de dados tem grande importância, pois define um padrão que representa uma aplicação viável no contexto de uma VTDN, levando em consideração o atraso e as demais características inerentes ao tipo de rede. Neste trabalho iremos utilizar um modelo de tráfego que representa uma aplicação de monitoramento. Para esta aplicação, assumimos que cada um dos 1280 veículos precisa informar, frequentemente, informações referente à sua posição geográfica, bem como dados relativos ao monitoramento à uma central de processamento.

Aplicações similares voltadas para o contexto de monitoramento de veículos normalmente utilizam a infraestrutura da rede celular para o envio de dados, fator que pode gerar custos elevados. Em Curitiba, segundo a [Companhia de Urbanização da Cidade de Curitiba 2017], entre março de 2016 e fevereiro de 2017 , foram gastos $\mathrm{R} \$ 882.785,16$ com serviços $3 \mathrm{G} / 4 \mathrm{G}$ para tal finalidade.

A localização da central de recepção das mensagens, demonstrada na figura 1 foi escolhida, não só devido à sua posição central em Curitiba, mas sobretudo devido a ser um dos pontos com maior concentração de linhas de ônibus na cidade, o que em teoria deve favorecer a possibilidade de entrega dos dados.

\section{Proposta}

A motivação que impulsionou as modificações realizadas no protocolo Spray and Wait surgiu do fato de que os protocolos de roteamento atuais parecem tirar pouco proveito 
das características inerentes do sistema de transporte coletivo em suas decisões de encaminhamento. Assim, propostas de alterações foram apresentadas e testadas, sendo escolhida para utilização no presente trabalho a qual obteve os melhores resultados dentre as simulações realizadas com as modificações no protocolo.

A proposta utilizada baseia-se principalmente na categorização dos veículos do transporte coletivo em classes, de acordo com a sua proximidade lógica com o destino, baseando-se nas conexões formadas por esses veículos. Inicialmente as classes de todos os veículos são definidas com o valor 10 . Se o veículo tem contato com o destino, sua classe é definida com o valor 0 . Se o veículo é de classe diferente de 0 e tem contato com um veículo de classe 0 , sua classe é definida com o valor 1 . A mesma lógica é implementada, sucessivamente para as demais classes.

O objetivo é que as classes dos veículos sejam definidas durante a execução da simulação, de acordo com os contatos do veículo. Como cada classe possui um valor, torna-se possível priorizar a entrega para veículos de uma classe melhor (mais baixa). Por padrão, o protocolo Spray and Wait em sua forma binária transmite metade das cópias a cada encontro com um nó vizinho, assim sucessivamente, até que cada nó fique com apenas uma cópia da mensagem, momento em que o nó deixa de transmitir a mensagem em questão e entra na fase de espera. A alteração nessa versão do protocolo faz com que, caso a classe do veículo de origem seja maior (ou seja, pior) do que a classe do veículo vizinho, uma réplica da mensagem em questão seja prioritariamente adicionada à fila de envio, mesmo que essa seja a última cópia da mensagem (nesse caso, é como se fosse gerada uma réplica adicional a ser transmitida para o veículo de melhor classe).

Sempre que o nó de origem encontra um vizinho de classe melhor, o mesmo sai do estado espera (caso se encontre nesse estado) para transmitir uma cópia adicional da mensagem para esse vizinho, em teoria com melhores condições de proceder com a entrega da mensagem. Isso permite utilizarmos um valor mais baixo para o parâmetro "número de cópias"do Spray and Wait, já que a pulverização inicial pode ser reduzida em um primeiro momento (quando os veículos ainda não tem suas classes definidas) e priorizada a partir do momento em que essas classes vão sendo definidas. Nas simulações realizadas, utilizamos o valor escolhido de 5 cópias para o protocolo Spray and Wait por ser, dentre os valores testados o que obteve as melhores taxas de entrega sem acrescentar uma sobrecarga desnecessária à rede.

\section{Resultados}

Ao executar cada simulação, uma série de parâmetros deve ser definida. Primeiramente é necessário escolher uma faixa de horário de funcionamento dos ônibus. Uma vez que cada faixa de horário possui uma quantidade de veículos e linhas diferentes, optou-se pela faixa de horário P1 (horário da manhã, das $05 \mathrm{~h} 30$ às 08h30), já que este período, com 1280 veículos distribuídos em 267 linhas apresenta a maior densidade de veículos no ambiente, o que favorece o número de encontros e uma maior troca de mensagens. Outro parâmetro a ser definido é o raio de alcance de comunicação entre os veículos, o qual está intimamente ligado à taxa de transmissão utilizada. Embora o alcance máximo teórico do padrão WAVE seja de $1.000 \mathrm{~m}$, experimentos reais sugerem alcances mais conservadores. [Almeida et al. 2018] realizaram uma série de experimentos utilizando dispositivos reais que suportam o protocolo 802.11 p, concluindo que a modulação associada a taxa de 
Tabela 1. Parâmetros utilizados nas simulações

\begin{tabular}{ll}
\hline \multicolumn{1}{c}{ Parâmetro } & \multicolumn{1}{c}{ Valor } \\
\hline Simulador & One \\
Tempo de simulação & $180 \mathrm{~min}$ \\
Quantidade de linhas & 267 \\
Quantidade de veículos & 1280 \\
Aplicação & Monitoramento \\
Raio de comunicação & $500 \mathrm{~m}$ \\
Taxa de transmissão & $12 \mathrm{Mb} / \mathrm{s}$ \\
TTL & $180 \mathrm{~min}$ \\
Tamanho do buffer & $250 \mathrm{MB}$ \\
Intervalo de geração de pacotes & $5 \mathrm{~min}, 10 \mathrm{~min}$ \\
Pacotes gerados até & $8000 \mathrm{segundos}$ \\
Tamanho do pacote & $5 \mathrm{~KB}$ \\
\hline
\end{tabular}

$12 \mathrm{Mbps}$ oferece um alcance satisfatório de $500 \mathrm{~m}$.

Por fim, o tamanho das mensagens foi definido em 5KB, e seu TTL em 180min (tempo total da simulação) para evitar que as mesmas expirassem no decorrer da simulação e o buffer foi configurado com o tamanho de $250 \mathrm{MB}$, suficiente para suportar a quantidade de cópias geradas de modo a não causar impacto negativo na rede. Além disso, foi definido um tempo limite para a geração de novas mensagens em $8.000 \mathrm{~s}$. O objetivo de tal limite é oferecer uma possibilidade de entrega de todas as mensagens geradas, e o valor foi definido baseado na latência média das mensagens verificada no decorrer das simulações. A tabela 1 resume as configurações utilizadas nas simulações.

\subsection{Métricas de Desempenho}

$\mathrm{Na}$ avaliação dos protocolos, utilizou-se as seguintes métricas de desempenho para comparar os resultados obtidos:

- Taxa de Entrega: Representa o percentual das mensagens criadas (MC) que efetivamente foram entregues (ME) definida pela equação 1 .

$$
\text { TaxaDeEntrega }=\frac{M C}{M E} * 100
$$

- Atraso Médio: Representa o tempo médio decorrido da criação até a entrega ao destino das mensagens efetivamente entregues, definido pela equação 2.

$$
\text { AtrasoMedio }=\frac{\sum_{\text {MEatrasos }}}{M E}
$$

- Sobrecarga: Representa a relação entre a quantidade de mensagens réplicas (MR) transmitidas e a quantidade de mensagens entregues (ME), definida pela equação 3.

$$
\text { Sobrecarga }=\frac{M R-M E}{M E}
$$




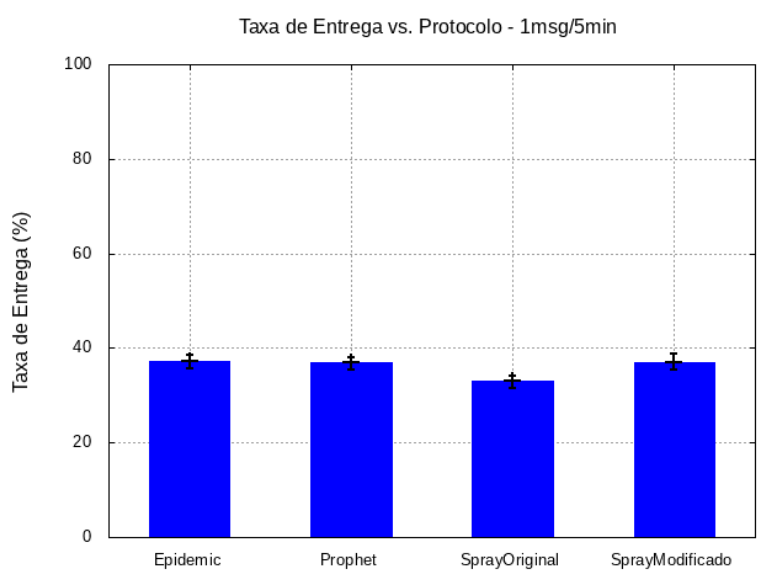

(a)

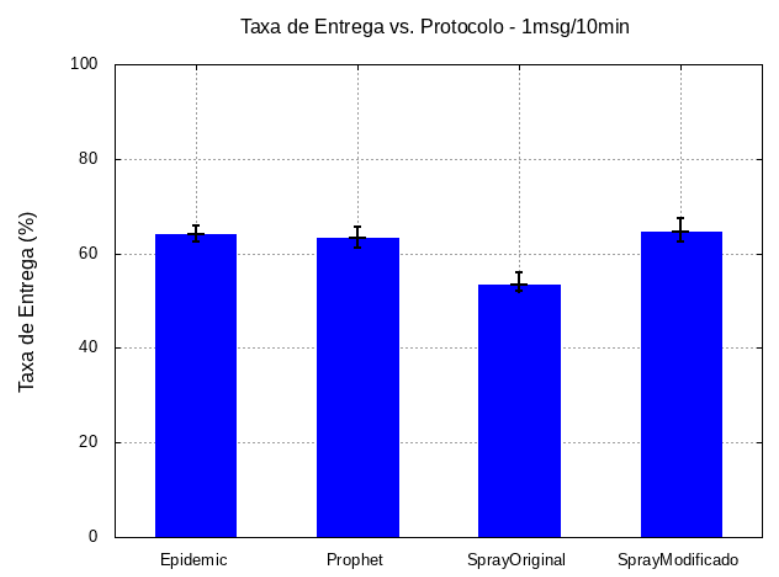

(b)

Figura 2. Taxa de entrega dos protocolos simulados. Os protocolos Epidêmico, Prophet e Spray and Wait modificado apresentaram resultados similares.

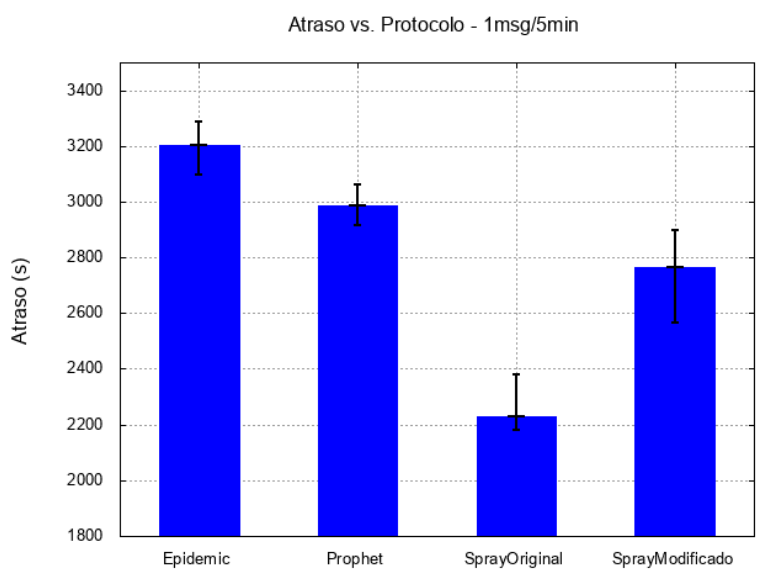

(a)

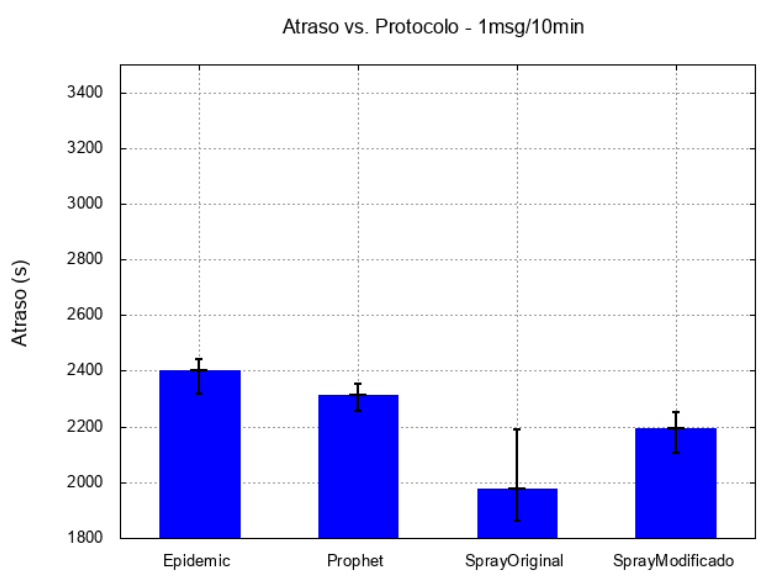

(b)

Figura 3. Atraso médio dos protocolos simulados. Percebe-se que o protocolo Spray and Wait original, apesar da taxa de entrega inferior, obteve os melhores resultados.

\subsection{Avaliação de Desempenho}

Os resultados apresentados foram obtidos realizando as simulações com os parâmetros informados em 5 dias úteis diferentes, com um intervalo de confiança de $95 \%$.

A figura 2 apresenta os resultados obtidos para a taxa de entrega, utilizando os protocolos Epidêmico, Prophet, Spray and Wait e Spray and Wait modificado, para os intervalos de geração de mensagens de 5 e 10min. Nota-se que, para ambos intervalos, a taxa de entrega dos protocolos Epidêmico, Prophet e Spray and Wait modificado são similares, e superiores ao protocolo Spray and Wait original.

A figura 3 apresenta os resultados obtidos para o atraso médio, utilizando os protocolos Epidêmico, Prophet, Spray and Wait e Spray and Wait modificado, para os intervalos de geração de mensagens de 5 e $10 \mathrm{~min}$. Os resultados indicam maior latência na 


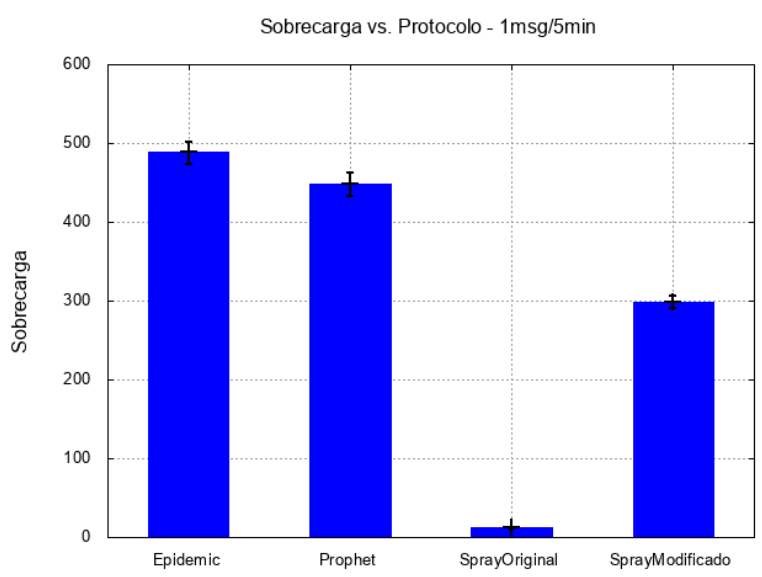

(a)

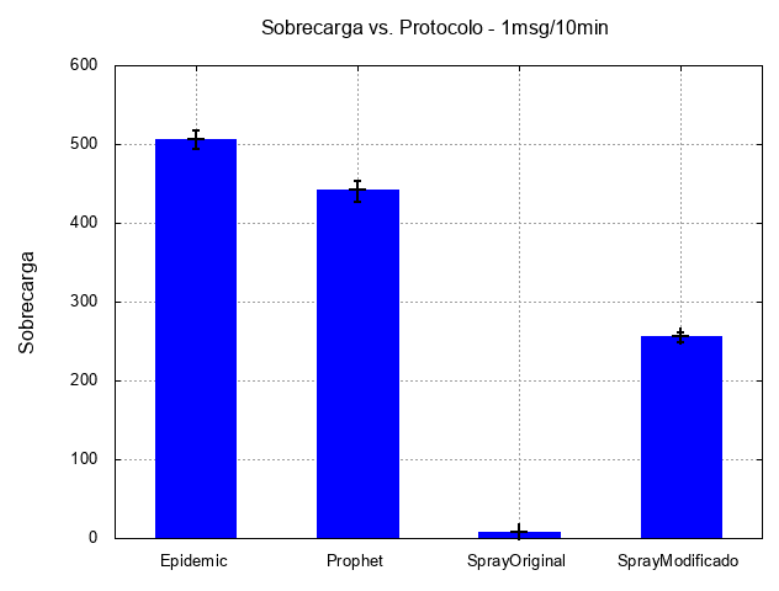

(b)

Figura 4. Sobrecarga dos protocolos simulados. O gráfico aponta menor sobrecarga para o protocolo Spray and Wait original.

entrega ao utilizar o protocolo Epidêmico, seguido pelo Prophet e pelos protocolos Spray and Wait, modificado e original. O fato do protocolo Spray and Wait original apresentar a entrega mais rápida, pode indicar que as mensagens entregues pelo mesmo são geradas mais próximas ao destino.

A figura 4 apresenta os resultados obtidos para a sobrecarga, utilizando os protocolos Epidêmico, Prophet, Spray and Wait e Spray and Wait modificado, para os intervalos de geração de mensagens de 5 e $10 \mathrm{~min}$. Os resultados indicam que as maiores sobrecargas ficam por conta dos protocolos Epidêmico e Prophet, enquanto que o protocolo Spray and Wait modificado apresenta um sobrecarga consideravelmente menor e o protocolo Spray and Wait apresenta uma sobrecarga próxima de zero. Uma sobrecarga baixa não necessariamente indica que o protocolo é o mais eficiente, uma vez que a sobrecarga está ligada diretamente à quantidade de mensagens entregues.

\subsection{Mapas de Calor}

$\mathrm{Na}$ análise dos resultados obtidos, é fácil a visualização de quais protocolos obtêm a melhor taxa de entrega para o cenário proposto. Porém, ao analisar apenas os números, eventualmente pode-se deixar de ter uma visão mais precisa do que realmente está ocorrendo durante a simulação, quais áreas estão sendo melhores atendidas e quais áreas apresentam um alto índice de mensagens não entregues. Além de enriquecer o trabalho, tais informações são cruciais para auxiliar a validar os resultados e ainda propor melhorias aos protocolos simulados.

Uma técnica que pode ser empregada para uma visualização mais precisa da taxa de mensagens entregues por região é a utilização de mapas de calor a partir dos dados obtidos através da simulação. Para alcançar tal objetivo, foi adicionado à saída do relatório de mensagens criadas a coordenada geográfica na qual a mesma foi gerada. As mensagens foram divididas em mensagens entregues e mensagens não entregues, e um script foi utilizado para converter as coordenadas para o formato EPSG:3857 Pseudo Mercator [EPSG.IO 2019], de modo a ser possível projetar as mesmas sobre o mapa da cidade de 


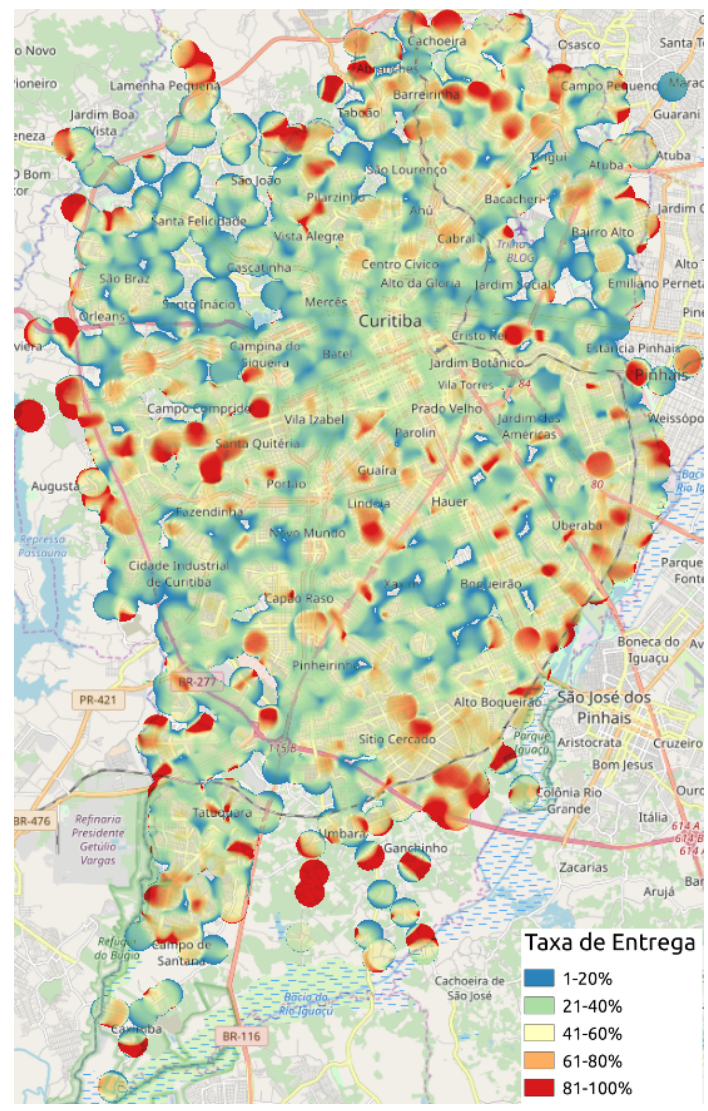

(a)

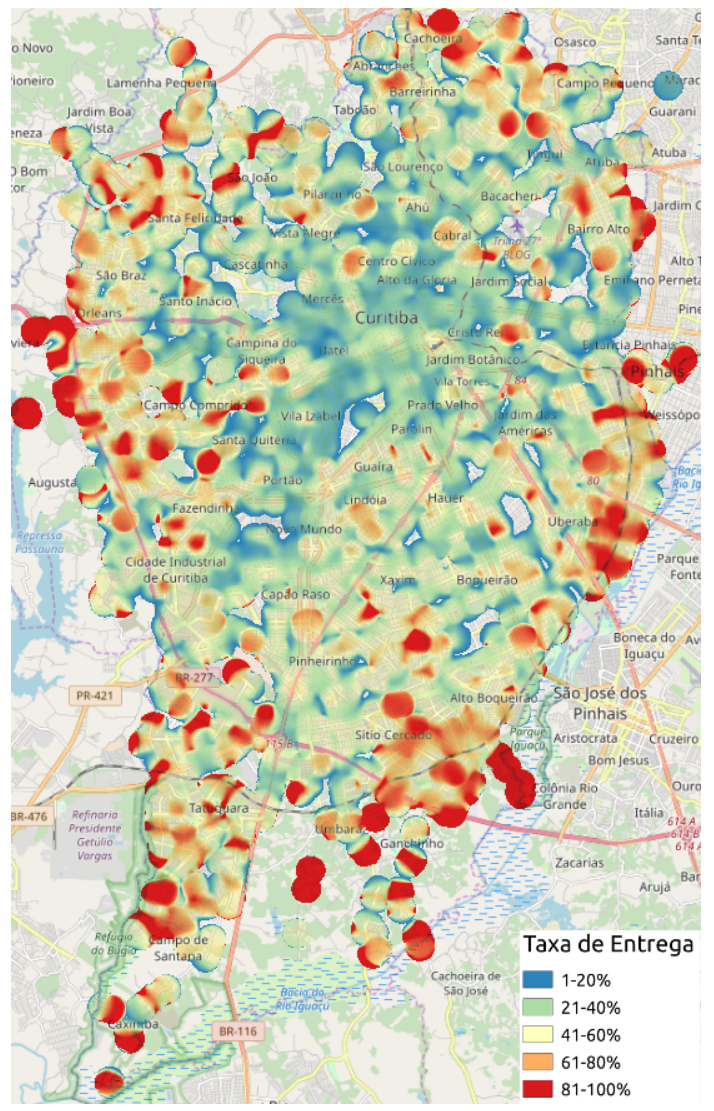

(b)

Figura 5. Mapas de calor das mensagens entregues pelos protocolos Epidêmico (a) e Prophet (b) indicam certa similaridade no comportamento dos dois protocolos.

Curitiba. Para gerar o mapa de calor foi utilizado o software QGIS [QGIS 2019] em sua versão 3.4.13 com o kernel shape definido como Quartico e raio de $500 \mathrm{~m}$ para a geração dos pontos de calor. A fim de exibir a taxa de entrega média em cada região da cidade, dividiu-se os dados matriciais das mensagens entregues pelos dados relativos à todas as mensagens geradas (entregues e não entregues).

A figura 5 apresenta os mapas de calor obtidos para as protocolos Epidêmico e Prophet, enquanto que a figura 6 ilustra os mapas de calor para os protocolos Spray and Wait original e modificado. Ambos utilizam mensagens entregues utilizando um intervalo de geração de mensagens a cada 5 minutos.

Nota-se certa similaridade entre os mapas de calor gerados para os protocolos Epidêmico e Prophet, sendo a diferença mais perceptível o fato de que o Epidêmico prioriza a entrega das mensagens geradas na região central da cidade em relação ao Prophet, que entrega de maneira mais eficiente as mensagens geradas na periferia da cidade.

Já as diferenças entre os protocolos Spray and Wait original e modificado, representadas pela figura 6 são bastante perceptíveis. Enquanto o protocolo modificado exibe uma alta taxa de entrega na região central e se estendendo principalmente para o leste, o protocolo original concentra quase que a totalidade das suas mensagens entregues na região central da cidade. Ao mesmo tempo que isso indica uma limitação do protocolo em 


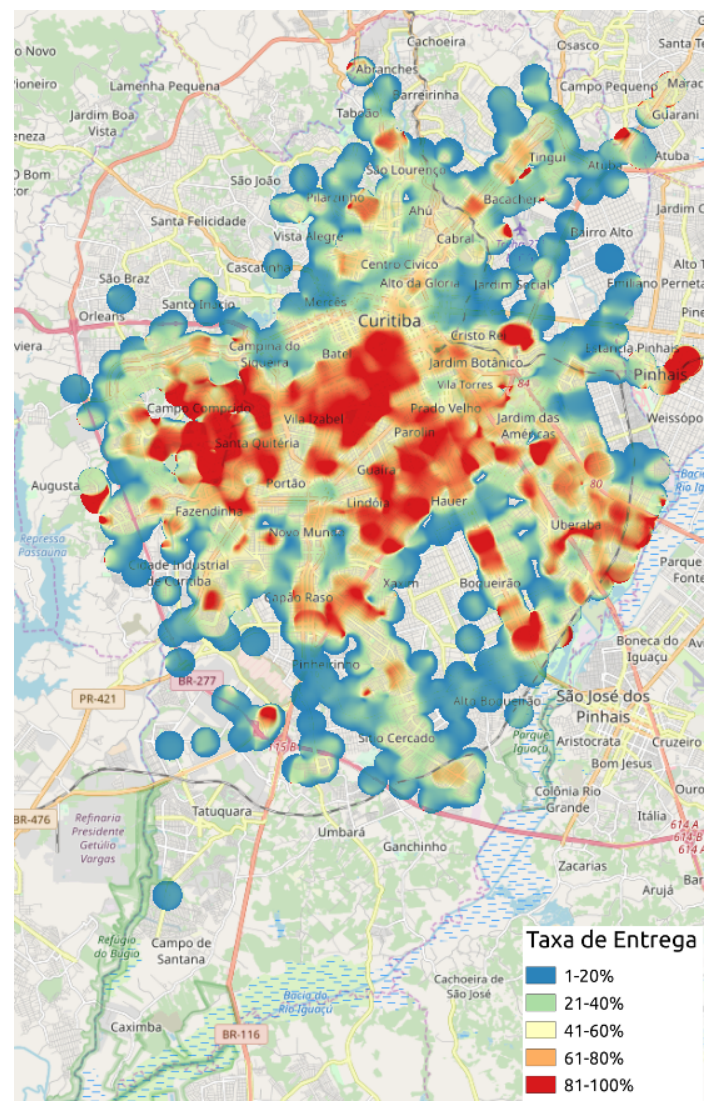

(a)

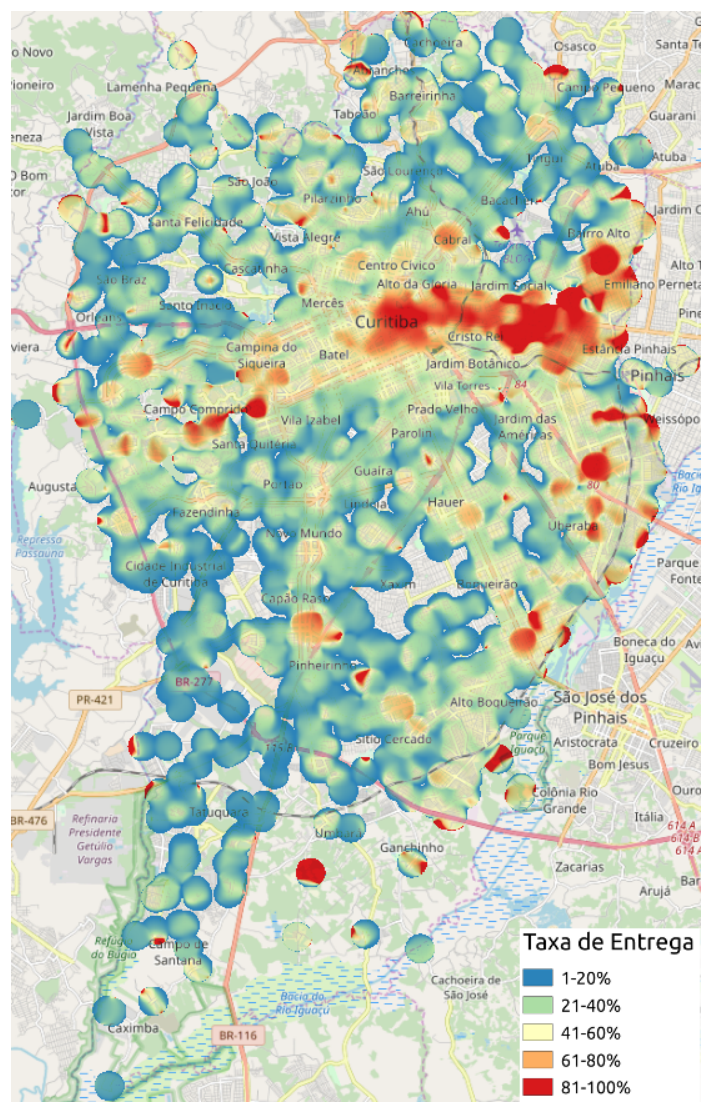

(b)

Figura 6. Mapas de calor das mensagens entregues pelos protocolos Spray and Wait original (a) e modificado (b) indicam que o primeiro atende melhor a região central, enquanto que o segundo apresenta uma melhor distribuição das mensagens entregues.

entregar mensagens que foram geradas em pontos distantes do destino, também ressalta o fato de que, mesmo com uma menor taxa de entrega em relação aos outros protocolos, ele acaba por concentrar a entrega de mensagens que foram geradas mais próximas do destino, provavelmente devido à sua baixa sobrecarga. Já as modificações do protocolo Spray and Wait que acabam por priorizar as linhas expressas são refletidas no mapa.

\section{Conclusão}

Neste artigo foi apresentada uma proposta de modificação do protocolo Spray and Wait, visando a priorização das mensagens transmitidas para veículos com uma maior proximidade lógica com o destino, informação representada por classes. As simulações indicaram que, comparada a versão original do protocolo Spray and Wait, a versão modificada obteve um ganho médio na taxa de entrega de $12,46 \%$ para mensagens geradas a cada 5 minutos e $20,87 \%$ para mensagens geradas a cada 10 minutos, mantendo uma taxa similar aos protocolos Epidêmico e Prophet, porém apresentando uma sobrecarga até 38,89\% menor que o protocolo Epidêmico e 33,40\% menor que o Prophet para mensagens geradas a cada 5 minutos. Ao utilizar uma taxa de geração de mensagens de 1 a cada 10 minutos, o protocolo Spray and Wait modificado obteve uma redução de até 49,54\% na sobrecarga comparado ao protocolo Epidêmico e 42,24\% comparado ao protocolo Prophet. 
Relativo ao atraso médio, para uma taxa de geração de mensagens de 1 a cada 5 minutos, as mensagens foram entregues pelo protocolo Spray and Wait modificado em um tempo 13,74\% menor quando comparado ao protocolo Epidêmico e até 7,45\% menor quando comparado ao Prophet. Já para o cenário com uma taxa de geração de mensagens de 1 a cada 10 minutos, o tempo de entrega foi até 8,78\% menor quando comparado ao protocolo Epidêmico e até 5,25\% menor quando comparado ao Prophet.

Os valores de sobrecarga e atraso médio apresentados pelo protocolo Spray and Wait original foram melhores quando comparados aos outros protocolos, porém sua baixa taxa de entrega, aliado ao fato de que a entrega realizou-se basicamente na região central devem ser relevados ao analisar tais resultados. De maneira geral, concluímos que, consideradas todas as métricas, o protocolo Spray and Wait modificado teve o melhor resultado, pois apresentou a melhor taxa de entrega, juntamente com os protocolos Epidêmico e Prophet, porém apresentando menores valores de latência e sobrecarga que os mesmos.

A análise dos mapas de calor tem como objetivo entender o funcionamento de cada protocolo, procurando formas de potencializar as características positivas e amenizar as características negativas dos mesmos. Já os protocolos que apresentam uma alta taxa de sobrecarga apresentam maior dificuldade em entregar as mensagens geradas na região central, o que condiz com o fato de que, proporcionalmente, a maior parte das mensagens são geradas nessa região, na qual trafegam mais veículos. Uma estratégia viável para trabalhos futuros seria propor alterações que diminuam a sobrecarga desses protocolos, com o objetivo de melhorar a taxa de entrega nas regiões centrais. Na sequência de realização dos trabalhos, pretende-se executar simulações aumentando a quantidade de antenas para recepção de mensagens, e posicioná-las tanto na região central quanto em regiões periféricas, realizando uma análise comparativa dos protocolos simulados.

\section{Referências}

Ahmed, S. H., Kang, H., and Kim, D. (2015). Vehicular Delay Tolerant Network (VDTN): Routing perspectives. 2015 12th Annual IEEE Consumer Communications and Networking Conference, CCNC 2015, pages 898-903.

Almeida, T. T., Gomes, L. D. C., and Ortiz, F. M. (2018). Analise de Desempenho do IEEE 802 . 11p : Simlações versus Experimentos Reais. Sbrc 2018.

Awang, A., Husain, K., Kamel, N., and Aissa, S. (2017). Routing in Vehicular Ad-hoc Networks: A Survey on Single- and Cross-Layer Design Techniques, and Perspectives. IEEE Access, 5:9497-9517.

Companhia de Urbanização da Cidade de Curitiba (2017). https://www.urbs.curitiba.pr.gov.br/.

Dados Abertos URBS (2019). http://dadosabertos.c3sl.ufpr.br/curitibaurbs/.

Dias, D. and Costa, L. (2016). Análise da Capacidade de Dados de uma Rede de Ônibus Urbanos.

EPSG.IO (2019). https://epsg.io/3857.

Fiore, M., Barcelo-Ordinas, J. M., Trullols-Cruces, O., and Uppoor, S. (2014). Generation and Analysis of a Large-Scale Urban Vehicular Mobility Dataset. IEEE Transactions on Mobile Computing, 13(5):1. 
Herek, T. A. (2018). Analise de uma rede oportunista no transporte público urbano e proposta de novos protocolos de roteamento adaptados. $\mathrm{PhD}$ thesis, Universidade Tecnológica Federal do Paraná.

Herek, T. A., Munaretto, A., Fonseca, M. S. P., and Monego, H. I. D. (2018). Analise da Capacidade de Entrega de uma Rede Oportunista no Transporte Público. In Simpósio Brasileiro de Redes de Computadores e Sistemas Distrbuídos-(SBRC).

Instituto Brasileiro de Geografia e Estatistica (2017). https://www.ibge.gov.br/.

Instituto de Pesquisa e Planejamento Urbano de Curitiba (2017). http://ippuc.org.br/.

Kai, K., Cong, W., and Tao, L. (2016). Fog computing for vehicular Ad-hoc networks: Paradigms, scenarios, and issues. Journal of China Universities of Posts and Telecommunications, 23(2):56-65,96.

Kakkasageri, M. S. and Manvi, S. S. (2014). Information management in vehicular ad hoc networks: A review. Journal of Network and Computer Applications, 39(1):334-350.

Keränen, A., Ott, J., and Kärkkäinen, T. (2009). The ONE simulator for DTN protocol evaluation. In SIMUTools '09: Proceedings of the 2nd International Conference on Simulation Tools and Techniques.

Lindgren, A. (2012). Probabilistic Routing Protocol for Intermittently Connected Networks.

QGIS (2019). https://www.qgis.org/en/site/.

Radu, D., Avram, C., Aştilean, A., Parrein, B., and Yi, J. (2012). Acoustic noise pollution monitoring in an urban environment using a VANET network. 2012 IEEE International Conference on Automation, Quality and Testing, Robotics, AQTR 2012 Proceedings, pages 244-248.

Spyropoulos, T., Psounis, K., and Raghavendra, C. S. (2005). Spray and wait: An efficient routing scheme for intermittently connected mobile networks. Proceedings of the ACM SIGCOMM 2005 Workshop on Delay-Tolerant Networking, WDTN 2005, pages 252259.

Tudose, D. S., Patrascu, T. A., Voinescu, A., Tataroiu, R., and Tapus, N. (2011). Mobile sensors in air pollution measurement. Proceedings of the 8th Workshop on Positioning Navigation and Communication 2011, WPNC 2011, pages 166-170.

Uchida, N., Hirakawa, G., Ishida, T., Arai, Y., and Shibata, Y. (2015). IEEE802.11 Based Vehicle-to-Vehicle Delay Tolerant Networks for Road Surveillance System in Local Areas. Proceedings - 2015 9th International Conference on Innovative Mobile and Internet Services in Ubiquitous Computing, IMIS 2015, pages 28-33.

Vahdat, A. and Becker, D. (2000). Epidemic Routing for Partially-Connected Ad Hoc Networks.

Zhang, F., Liu, H., Leung, Y. W., Chu, X., and Jin, B. (2017). CBS: Community-Based Bus System as Routing Backbone for Vehicular Ad Hoc Networks. IEEE Transactions on Mobile Computing, 16(8):2132-2146. 